\section{Intra-pleural colistin methanesulfonate therapy for pleural infection caused by carbapenem-resistant Acinetobacter baumannii: a successful case report}

\author{
Muhammad Asim Rana, \\ Basheer Abd El Rahman, ${ }^{1}$ \\ Ahmed Fouad Mady, ${ }^{1}$ \\ Mohammed Al Odat, ${ }^{1}$ \\ Abdurehman AlHarthy, ${ }^{1}$ \\ Omar El Sayed Ramadan, ${ }^{1}$ \\ Shahzad Ahmed Mumtaz, ${ }^{1}$ Ali S. Omrani ${ }^{2}$ \\ 'Intensive Care Medicine, King Saud \\ Medical City, Riyadh; 'Division of \\ Infectious Diseases, Prince Sultan \\ Military Medical City, Riyadh, Saudi \\ Arabia
}

\section{Abstract}

Infections caused by carbapenem-resistant, Gram-negative bacteria are an increasing clinical challenge, since the antimicrobial treatment options are often limited to colistin methanesulfonate. No data are available regarding the pharmacokinetics of colistin in pleural fluid. We report the case of a 92-year old man with ventilator-associated pneumonia and pleurisy caused by Acinetobacter baumannii and Escherichia coli, which were both multidrug-resistant. After an unsuccessful treatment with intravenous colistin methanesulfonate and imipenem-cilastatin, the addition of intra-pleural colistin methanesulfonate to the intravenous treatment led to a prompt clinical, radiological and microbiological resolution. This is the first report of a successful use of intra-pleural colistin in the literature. The intra-pleural colistin therapy should be considered in selected cases of pleurisy caused by multi-resistant Gram-negative bacteria.

\section{Case Report}

A 92-year old male resident in a nursing home was admitted to our tertiary care center in Riyadh, Saudi Arabia, with a general deterioration. He had a past history of diabetes mellitus, systemic hypertension and stroke. The physical examination revealed a temperature of $34^{\circ} \mathrm{C}$, blood pressure of $70 / 30 \mathrm{mmHg}$, pulse rate of 115 per minute, respiratory rate of 22 per minute and a Glasgow Coma Scale of 8 out of 15. A temporary diagnosis of urinary tract infection and septic shock was made and he was transferred to the intensive care unit, where he received intravenous fluids, vasopressors and mechanical ventilation. The initial empiric antimicrobial therapy included imipenem-cilastatin four times daily and ciprofloxacin $400 \mathrm{mg}$ twice daily, both given intravenously. The blood, urine and sputum cultures showed an extended-spectrum betalactamase (ESBL)-producing Escherichia coli. The isolates were resistant to ciprofloxacin, but susceptible to imipenem and gentamicin (Table 1). Ciprofloxacin was therefore replaced with intravenous gentamicin $120 \mathrm{mg}$ three times daily. The clinical conditions of the patient improved and gentamicin and imipenem-cilastatin were discontinued after a total of 10 days and 14 days respectively.

Ten days after the antibiotic therapy was discontinued, i.e. on the $24^{\text {th }}$ day in the intensive care unit, the patient had fever up to $38.6^{\circ} \mathrm{C}$, hypotension and peripheral blood leukocytosis (white blood cell count $18 \times 10^{9} / \mathrm{L}$, $80 \%$ neutrophils). There was a dull percussion sound and reduced breath sounds in the left lung. Chest x-ray showed left lung consolidation with a large pleural effusion (Figure 1a). A pigtail catheter was inserted taking strict aseptic precautions to drain the effusion (Figure 1b). The fluid analysis revealed protein at $52.0 \mathrm{~g} / \mathrm{L}$, lactate dehydrogenase at 1477 $\mathrm{IU} / \mathrm{L}, \mathrm{pH}$ at 7.0 and white blood cells at 8450 , $96 \%$ of which were neutrophils. A diagnosis of ventilator-associated pneumonia and pleurisy was made and colistin methanesulfonate was started with a loading dose of 9 million units followed 24 hours later by 3 million units three times daily in combination with imipenemcilastatin $500 \mathrm{mg}$ four times daily. The patient developed a pneumothorax because of the pigtail catheter which was therefore replaced with an intercostal chest drain (Figure 1c). The pleural fluid taken via the pigtail drain showed the growth of ESBL-producing $E$. coli and carbapenem-resistant Acinetobacter baumannii.

On day 28, the patient was still febrile and continued to require high dose vasopressor infusions to maintain his blood pressure. The lack of clinical improvement prompted us to add intra-pleural colistin methanesulfonate at a dose of 0.5 million units in $50 \mathrm{~mL}$ of a $0.9 \%$ sodium chloride solution. The medication was administered at 12-hour intervals via the intercostal drain. In between the drain was clamped for 2 hours before the drainage was resumed. By day 33, a remarkable improvement in the patient's condition was noted with a drop of the peripheral white blood cell count to $8.8 \times 10^{9} / \mathrm{L}$ (normal range: $4-11 \times 10^{9} / \mathrm{L}$ ), reduced need for ventilation and successful discontinuation of the vasopressor support. A sample of pleural fluid was taken on day 34 . It showed the growth of Proteus mirabilis (Table 1), but neither $A$. baumannii nor $E$. coli were isolated, indicating a successful microbiological clear-
Correspondence: Muhammad Asim Rana, Intensive Care Medicine, King Saud Medical City, P0 Box 331140, Post Code 11373, Shumaisy, Riyadh, Saudi Arabia.

Tel.: +96.656.688.1506

E-mail: drasimrana@yahoo.com

Key words: multi drug resistant, Gram negative bacteria, Colistin, Colistemethate sodium, Acinetobacter Baumannii, intrapleural infection.

Contributions: MAR, conceived the idea of the study, had a leading role in patient management, data collection and manuscript preparation; BAER, literature review and manuscript revision; AFM, MAO, OER, manuscript revision; AHA, data collection and manuscript revision; SAM, literature review, data collection and manuscript revision; ASO, literature review, manuscript revision and re-drafting.

Conflict of interests: the authors declare no potential conflict of interests.

Received for publication: 29 May 2014.

Revision received: 8 July 2014.

Accepted for publication: 14 July 2014.

This work is licensed under a Creative Commons Attribution NonCommercial 3.0 License (CC BYNC 3.0).

(C) Copyright M.A. Rana et al., 2014

Licensee PAGEPress, Italy

Infectious Disease Reports 2014; 6:5413

doi:10.4081/idr.2014.5413

ance of both microorganisms. The minimum inhibitory concentrations of imipenem and meropenem for the isolated Proteus mirabilis strain were $4 \mathrm{mg} / \mathrm{L}$ and $1 \mathrm{mg} / \mathrm{L}$ respectively, thus suggesting a switch from imipenem-cilastatin to meropenem $1 \mathrm{~g}$ three times daily intravenously. The intra-pleural and intravenous colistin methanesulfonate therapies were discontinued after a total of 10 days and 14 days, respectively, while meropenem was continued for a total of 7 days. Culture of pleural fluid obtained on day 37 was again negative for $A$. baumannii and $E$. coli (Table 1). The intercostal drain was removed on day 42 and a follow-up chest x-ray showed the resolution of the previously identified signs of infection and effusion (Figure 1d). Despite the patient remained clinically stable with no further episodes of sepsis, our attempts to wean him off mechanical ventilation were unsuccessful. He developed an acute myocardial ischemia and passed away after a total stay of 67 days in the intensive care unit. 


\section{Discussion}

To the best of our knowledge, this is the first report of successful intra-pleural colistin methanesulfonate therapy, in combination with intravenous antibiotics, for a pleural infection caused by multidrug-resistant gramnegative bacteria. Indeed, the patient had clinical, radiological and microbiological evidence of ventilator-associated pneumonia and pleural infection caused by multi-drug resistant strains of $E$. coli and A. baumannii. He remained critically ill with refractory hypotension, fever and leukocytosis despite 4 days of appropriately dosed intravenous imipenemcilastatin and colistin methanesulfonate therapy. The addition of intra-pleural colistin methanesulfonate was associated with a prompt clinical and microbiological response. Intra-pleural antimicrobial therapy is not generally recommended in the treatment of bacterial pleural infections. ${ }^{1,2}$ However, favorable results were reported from small comparative studies when intra-pleural antimicrobial therapy was added to an adequate pleural drainage and systemic antimicrobial therapy.-5 Many articles published in the literature described a poor colistin penetration in the pleural space, but none indicated a reference to corroborate this statement. ${ }^{6-11}$ We searched the English language literature using PubMed, Medline Plus and Google Scholar and were not able to identify any primary studies upon which these statements could be based.

Colistin was originally introduced in the clinical practice in the 1950's and hence was not submitted to the modern requirements for rigorous pre-licensing assessments. As a result, there are considerable gaps in the understanding of its clinical efficacy in various types of infections. ${ }^{6}$ Its clinical use has increased over the last two decades in parallel with the development and the spread of infections caused by carbapenem-resistant Gramnegative bacteria. ${ }^{6,12,13}$ It has become evident that the results of earlier colistin pharmacokinetic studies, which relied upon biological assays, are unreliable. ${ }^{13}$ Modern pharmacokinetic studies have demonstrated that previously recommended parenteral regimens lead to sub-therapeutic serum colistin levels, especially in critically-ill patients. ${ }^{14-16}$ The colistin
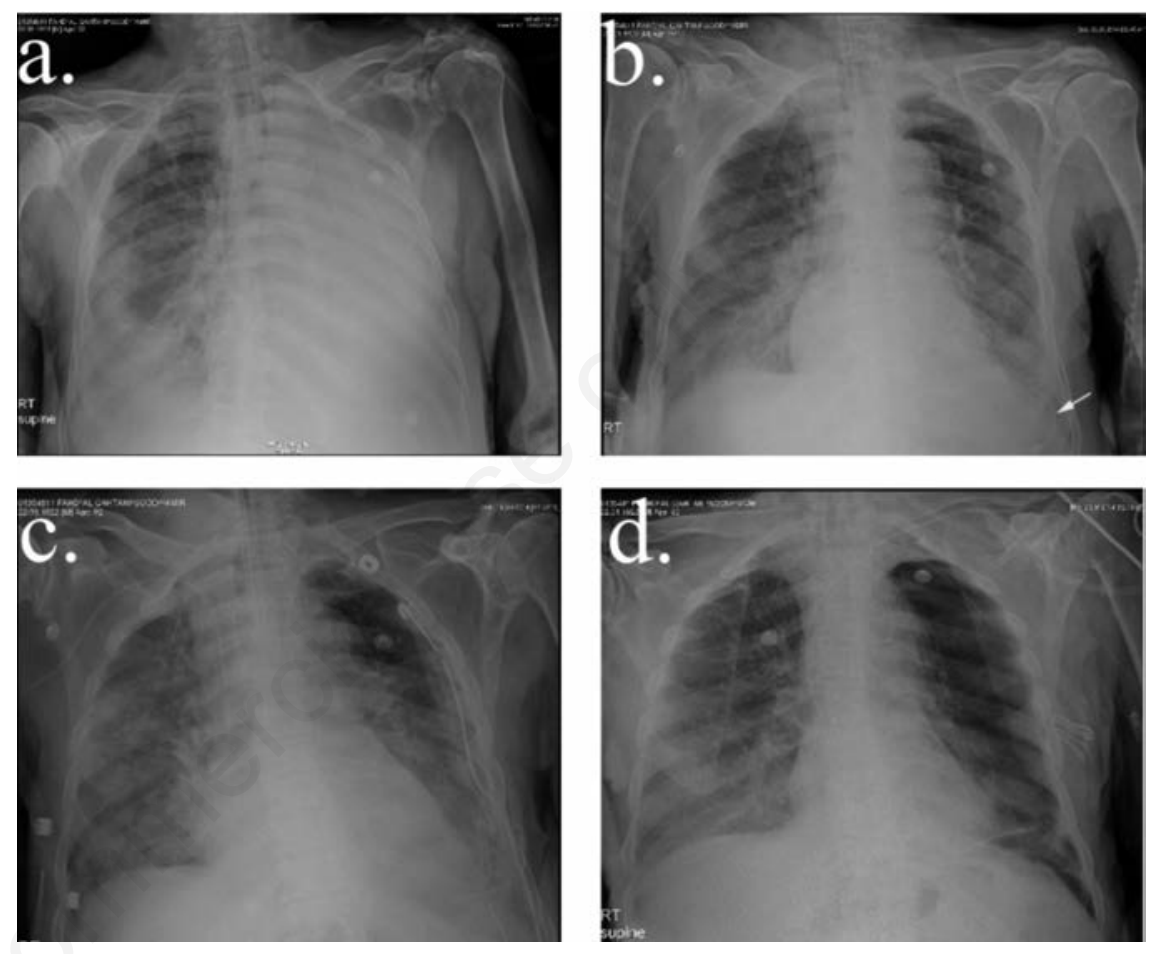

Figure 1. Serial chest radiographs. a) Day 24; left lung consolidation and large pleural effusion. b) Pigtail drain in left pleural space. c) Pigtail drain changed with intercostal tube because of pneumothorax. d) Post-therapy resolution of left-side pleural effusion.

Table 1. Culture and antimicrobial susceptibility testing results.

\begin{tabular}{|c|c|c|c|c|c|c|c|c|}
\hline Sample type & Date collecte & $\begin{array}{l}\text { Culture } \\
\text { result }\end{array}$ & Cefotaxime & $\begin{array}{l}\text { Antimic } \\
\text { Ciprofloxacin }\end{array}$ & $\begin{array}{l}\text { obial suscep } \\
\text { Gentamicin }\end{array}$ & $\begin{array}{l}\text { bility testing } \\
\text { Imipenem }\end{array}$ & $\begin{array}{l}\text { results* } \\
\text { Meropenem }\end{array}$ & Colistin \\
\hline Catheter sample urine & $7 / 2 / 14$ & E. coli ${ }^{\circ}$ & $\mathrm{R}$ & $\mathrm{R}$ & S $(\text { MIC 2.0) })^{\#}$ & S & $\mathrm{S}$ & - \\
\hline Peripheral venous blood & $7 / 2 / 14$ & E. coli ${ }^{\circ}$ & $\mathrm{R}$ & $\mathrm{R}$ & $\mathrm{S}(\mathrm{MIC} 2.0)^{\#}$ & S & S & - \\
\hline Peripheral venous blood & $7 / 2 / 14$ & E. coli ${ }^{\circ}$ & $\mathrm{R}$ & $\mathrm{R}$ & S (MIC 2.0)\# & S & S & - \\
\hline Endotracheal aspirate & $7 / 2 / 14$ & E. coli ${ }^{\circ}$ & $\mathrm{R}$ & $\mathrm{R}$ & $\mathrm{S}(\mathrm{MIC} 2.0)^{\#}$ & S & S & - \\
\hline \multirow[t]{2}{*}{ Pleural fluid } & \multirow[t]{2}{*}{$4 / 3 / 14$} & A. baumannii & $\mathrm{R}$ & $\mathrm{R}$ & $\mathrm{R}$ & $\mathrm{R}$ & $\mathrm{R}$ & S \\
\hline & & E. coli ${ }^{\circ}$ & $\mathrm{R}$ & $\mathrm{R}$ & $\mathrm{R}$ & $\mathrm{S}$ & S & $\mathrm{S}$ \\
\hline Pleural fluid & $13 / 3 / 14$ & P. mirabilis & $\mathrm{R}$ & $\mathrm{R}$ & $\mathrm{R}$ & S $(\text { MIC } 4.0)^{\#}$ & S (MIC 1.0)\# & $\mathrm{R}$ \\
\hline Peripheral venous blood & $15 / 3 / 14$ & No bacterial growth & - & - & - & - & - & - \\
\hline Peripheral venous blood & $15 / 3 / 14$ & No bacterial growth & - & - & - & - & - & - \\
\hline Urine & $15 / 3 / 14$ & No bacterial growth & - & - & - & - & - & - \\
\hline Pleural fluid & $19 / 3 / 14$ & P. mirabilis & $\mathrm{R}$ & $\mathrm{R}$ & $\mathrm{R}$ & S $(\text { MIC } 4.0)^{\#}$ & S (MIC 1.0) & $\mathrm{R}$ \\
\hline
\end{tabular}

*Using disc diffusion methods and interpretation criteria recommended by the Clinical Laboratory Standards Institute (CLSI); ${ }^{\circ}$ Extended-spectrum beta-lactamase producing strain; ${ }^{*}$ minimum inhibitory concentration by Etest. 
excretion, we felt that in the presence of an intercostal drain, a twice daily administration might result in a better average exposure over time, thereby optimizing bacterial killing. ${ }^{21,22}$ Interestingly, the summary of product characteristics for at least one commercially available colistin methanesulfonate preparation, Colimicina (UCB Pharma, Pianezza, Italy), includes recommendation for intra-pleural and intra-peritoneal treatments with a dose of 0.5 1.0 million units per day mixed in $20-50 \mathrm{~mL}$ of ordinary saline. ${ }^{23}$ These routes of administration are not recommended in the product summary characteristics of the locally available brand of colistin methanesulfonate (Colomycin, Forest Laboratories, Bextley, United Kingdom). ${ }^{24}$

Despite the successful outcome in our case report, it is important to emphasize that the safety of the intra-pleural colistin therapy remains still to be established. Respiratory depression has previously been reported in association with the intra-pleural administration of neomycin and bacitracin therapy. ${ }^{25}$ Therefore, this adverse event should be taken into consideration for this route of administration. Moreover, it is not known whether this topical treatment could result in the development of bacterial resistance to colistin, as was the case with the inhalational colistin therapy in patients with cystic fibrosis. ${ }^{26}$

Finally, even though the patient improved during the intravenous treatment and the pleural draining, we believe that the addition of the topical intra-pleural medication had a key role in the clinical and microbiological improvement, as it emerged in connection with its introduction.

\section{Conclusions}

The use of the intra-pleural colistin therapy should be considered in carefully selected patients with pleural infections caused by multi-resistant Gram-negative bacteria. However appropriately designed trials and further studies are needed to better clarify the efficacy, the safety, and the pharmacokinetics of this route of colistin administration.

\section{References}

1. Bryant RE, Salmon CJ. Pleural empyema. Clin Infect Dis 1996;22:747-62.

2. Davies HE, Davies RJ, Davies CW, Group BTSPDG. Management of pleural infection in adults: British Thoracic Society pleural disease guideline 2010. Thorax

\section{0;65:ii41-53.}

3. Ader A, Reimer P, Kam R, et al. Feasibility of irrigation and instillation of antimicrobial or antibiotic solutions in patients with parapneumonic empyema. A prospective randomized study. Indian $\mathrm{J}$ Thorac Cardiovasc Surg 2008;24:184-90.

4. Duailibe LP, Donatti MI, Müller PdT, Dobashi PN. Treatment of empyema using thoracentesis with irrigation and intrapleural application of an antimicrobial agent. J Bras Pneumol 2004;30:215-22.

5. Mittapalli MR. Successful treatment of empyema with thoracocenteses and intrapleural antibiotics. South Med J 1980;73:533-4.

6. Falagas ME, SK K, Saravolatz LD. Colistin: the revival of polymyxins for the management of multidrug-resistant gram-negative bacterial infections. Clin Infect Dis 2005;40:1333-41

7. Michalopoulos AS, Falagas ME. Colistin: recent data on pharmacodynamics properties and clinical efficacy in critically ill patients. Ann Intens Care 2011;1:30.

8. Yahav D, Farbman L, Leibovici L, Paul M. Colistin: new lessons on an old antibiotic. Clin Microbiol Infect 2012;18:18-29.

9. Chen LF, Kaye D. Current use for old antibacterial agents: polymyxins, rifamycins, and aminoglycosides. Infect Dis Clin N Am 2009;23:1053-75.

10. Evans ME, Feola DJ, Rapp RP. Polymyxin B sulfate and colistin: old antibiotics for emerging multiresistant gram-negative bacteria. Ann Pharmacother 1999;33:9607.

11. Landman D, Georgescu C, Martin DA, Quale J. Polymyxins revisited. Clin Microbiol Rev 2008;21:449-65.

12. Alfahad WA, Omrani AS. Update on colistin in clinical practice. Saudi Med J 2014;35:919.

13. Li J, Nation RL, Turnidge JD, et al. Colistin: the re-emerging antibiotic for multidrug-resistant Gram-negative bacterial infections. Lancet Infect Dis 2006;6:589-601.

14. Imberti R, Cusato $M$, Villani $P$, et al. Steady-state pharmacokinetics and BAL concentration of colistin in critically Ill patients after IV colistin methanesulfonate administration. Chest 2010;138:1333-9.

15. Markou N, Markantonis SL, Dimitrakis E, et al. Colistin serum concentrations after intravenous administration in critically ill patients with serious multidrug-resistant, gram-negative bacilli infections: a prospective, open-label, uncontrolled study. Clin Ther 2008;30:143-51.

16. Plachouras D, Karvanen M, Friberg LE, et al. Population pharmacokinetic analysis of colistin methanesulfonate and colistin after intravenous administration in critically ill patients with infections caused by gram-negative bacteria. Antimicrob Agents Chemother 2009;53:3430-6.

17. Bergen PJ, Li J, Nation RL. Dosing of colistin-back to basic PK/PD. Curr Opin Pharmacol 2011;11:464-9.

18. Mohamed AF, Karaiskos I, Plachouras D, et al. Application of a loading dose of colistin methanesulfonate in critically ill patients: population pharmacokinetics, protein binding, and prediction of bacterial kill. Antimicrob Agents Chemother 2012;56:4241-9.

19. Karaiskos I, Galani L, Baziaka F, Giamarellou H. Intraventricular and intrathecal colistin as the last therapeutic resort for the treatment of multidrugresistant and extensively drug-resistant Acinetobacter baumannii ventriculitis and meningitis: a literature review. Int $\mathrm{J}$ Antimicrob Agents 2013;41:499-508.

20. Imberti R, Cusato M, Accetta G, et al. Pharmacokinetics of colistin in cerebrospinal fluid after intraventricular administration of colistin methanesulfonate. Antimicrob Agents Chemother 2012;56:4416-21.

21. Dudhani RV, Turnidge JD, Nation RL, Li J. fAUC/MIC is the most predictive pharmacokinetic/pharmacodynamic index of colistin against Acinetobacter baumannii in murine thigh and lung infection models. J Antimicrob Chemother 2010;65:1984-90.

22. Daikos GL, Skiada A, Pavleas J, et al. Serum bactericidal activity of three different dosing regimens of colistin with implications for optimum clinical use. J Chemother 2010;22:175-8.

23. Torrinomedica. Colimicina. Riassunto delle caratteristiche del prodotto. Available from: http://www.torrinomedica.it/farmaci/schedetecniche/Colimicina.asp. Accessed on: May 2014.

24. Electronic Medicines Compendium (eMC). Colomycin injection: summary of product characteristics. Available from: http://www.medicines.org.uk/emc/medicine/1590/SPC/Colomycin+Injection. Accessed on: May 2104.

25. Davidson EW, Modell JH, Moya F, Farmati 0 . Respiratory depression following use of antibiotics in pleural and pseudocyst cavities. JAMA 1966;196:456-7.

26. Johansen HK, Moskowitz SM, Ciofu 0, et al. Spread of colistin resistant non-mucoid Pseudomonas aeruginosa among chronically infected Danish cystic fibrosis patients. J Cyst Fibro 2008;7:391-7. 